\title{
Pelindian Neodymium dari Magnetik Coal Fly Ash menggunakan Asam Asetat sebagai Pelarut
}

\section{Leaching Neodymium from Magnetic Coal Fly Ash using Acetic Acid Solvent}

\author{
Haries Handoyo*, I Made Bendiyasa, Agus Prasetya \\ Department of Chemical Engineering (Sustainable Mineral Processing Research Group), \\ Universitas Gadjah Mada, Sleman, 55281, Indonesia
}

\section{Artikel histori : \\ Diterima 25 April 2019 \\ Diterima dalam revisi 18 Agustus 2019 Diterima 24 Oktober 2019 Online 31 Oktober 2019}

\begin{abstract}
ABSTRAK: Neodymium (Nd) telah dikenal sebagai komponen penting dalam industri modern diantaranya sebagai magnet permanen (magnet $\mathrm{NdFeB}$ ). Beberapa negara kini mulai mencari sumber alternatif $\mathrm{Nd}$ yang salah satunya adalah abu terbang batubara, yang merupakan hasil dari pembakaran batubara sebagai sumber energi listrik. Penelitian ini bertujuan untuk mempelajari pelindian $\mathrm{Nd}$ dari abu terbang batubara menggunakan asam asetat sebagai pelarut pada kondisi atmosferik. Pada penelitian ini dipelajari pengaruh konsentrasi asam asetat $(0,1-1,0 \mathrm{~N})$ dan pengaruh suhu pelindian $\left(26-60{ }^{\circ} \mathrm{C}\right)$. Beberapa kondisi percobaan yang dijaga tetap yaitu kecepatan pengadukan $(400 \mathrm{rpm})$, rasio $\mathrm{S} / \mathrm{L}(3,75 \% \mathrm{~W} / \mathrm{V})$ dan ukuran partikel (-400 mesh). Hasil pelindian tertinggi (72\%) diperoleh pada konsentrasi asam asetat 0,5 $\mathrm{N}$ pada $60{ }^{\circ} \mathrm{C}$. Hasil percobaan menunjukkan pelindian $\mathrm{Nd}$ dari magnetik CFA menggunakan asam asetat mengikuti model shringking core yang dikontrol oleh difusi lapisan abu: $\left[\mathrm{t} . \mathrm{k}_{\mathrm{ap}}=1-3\left(1-\mathrm{X}_{\mathrm{B}}\right)^{2 / 3}+2\left(1-\mathrm{X}_{\mathrm{B}}\right)\right]$, dengan energi aktivasi sebesar $15,38 \mathrm{~kJ} / \mathrm{mol}$.
\end{abstract}

Kata Kunci: neodymium; pelindian; magnetik CFA; asam asetat.

\begin{abstract}
Neodymium (Nd) has been known as a vital component in the modern industry such as for very strong permanent magnets (NdFeB magnet). Some countries are starting to look for alternative sources of $\mathrm{Nd}$ such as coal fly ash (CFA), which is the waste from coal combustion. This study aims to look at the potential for $\mathrm{Nd}$ extraction from CFA using acetic acid at atmospheric pressure. The effect of $\mathrm{CH}_{3} \mathrm{COOH}$ concentrations $(0,1-1,0 \mathrm{~N})$, and leaching temperature $\left(26-60{ }^{\circ} \mathrm{C}\right)$ was investigated. The experiment was carried out under a constant agitation speed $(400 \mathrm{rpm}), \mathrm{S} / \mathrm{L}$ ratio $(3,75 \%(\mathrm{~W} / \mathrm{V}))$ and CFA particle size (-400 mesh). The highest leaching eficiencies (72\%) were achieved for concentration of acetic acid $0,5 \mathrm{~N}$ at $60{ }^{\circ} \mathrm{C}$. The leaching kinetics results showed that it best fits the shrinking core model: $\left[\mathrm{t} . \mathrm{k}_{\mathrm{ap}}=1-3\left(1-\mathrm{X}_{\mathrm{B}}\right)^{2 / 3}+2\left(1-\mathrm{X}_{\mathrm{B}}\right)\right.$ ] ensuring the overall leaching process is controlled by difussion ash layer. The activation energy determined from the experimental study was of $15,38 \mathrm{~kJ} / \mathrm{mol}$.
\end{abstract}

Keywords: neodymium; leaching; magnetic CFA; acetic acid

\section{Pendahuluan}

Neodymium merupakan salah satu unsur dari golongan logam tanah jarang (LTJ) yang banyak digunakan di dunia industri karena berbagai sifatnya yang unggul. Neodymium dapat digunakan dalam pembuatan magnet permanen $\left(\mathrm{Nd}_{2} \mathrm{Fe}_{14} \mathrm{~B}\right)$ yang biasa digunakan sebagai komponen dari hard disk komputer, telepon genggam, wind turbine, dan motor listrik (Croat, 2018)(Zepf, 2013). Neodymium juga digunakan dalam pembuatan laser neodymium-yittriumaluminium-garnet (Nd-YAG) yang dapat digunakan untuk diagnosa glaukoma dan pengobatan kista (Jha, 2014).

Seiring dengan perkembangan teknologi yang mengarah ke teknologi yang ramah lingkungan serta semakin luasnya bidang industri yang memanfaatkan $\mathrm{Nd}$, maka kebutuhan pasar dunia akan $\mathrm{Nd}$ pun semakin

\footnotetext{
* Corresponding Author:

email: haries_handayani@yahoo.com
}

meningkat. Bahkan European Comission dan U.S. Department of Energy (DOE) sudah menggolongkan $\mathrm{Nd}$ sebagai material kritis, dengan definisi kritis adalah ketika risiko kekurangan pasokan bahan tersebut dan dampaknya terhadap ekonomi lebih tinggi dibandingkan dengan sebagian besar bahan baku lainnya (Voncken, 2016)(Blisset dkk., 2013).

Cina merupakan negara produsen yang mendominasi produksi LTJ di dunia hingga mencapai 97\% dari total produksi dunia pada saat ini (Jha, 2014). Adanya dominasi Cina dan sikap Cina yang tidak segan untuk menaikkan pajak ekspor LTJ, membatasi kuota ekspor, bahkan menghentikan ekspor LTJ ke negera yang berkonflik dengan Cina cukup mengkhawatirkan dunia industri yang memanfaatkan LTJ. Untuk mengatasi ketergantungan tersebut, banyak negara yang mulai mencari sumber alternatif LTJ dan mengembangkan teknologi pengolahannya secara mandiri. 
Logam tanah jarang termasuk neodymium biasanya diperoleh dari batuan mineralnya seperti bastnesite $(\mathrm{La}, \mathrm{Ce}) \mathrm{FCO}_{3}$, monasite $(\mathrm{Ce}, \mathrm{La}, \mathrm{Y}, \mathrm{Th}) \mathrm{PO}_{4}$ dan Xenotime $\left(\mathrm{YPO}_{4}\right)$ (Croat, 2018) (Zepf, 2013). Selain dari mineral tersebut, LTJ juga ditemukan dalam batubara dan limbah hasil pembakaran batubara yaitu coal fly ash (CFA) (Eskenazy, 1987)(Seredin, 1996)(Belkin dkk., 2009) (Dai dkk., 2012)(Blisset dkk., 2014).

Indonesia mempunyai cadangan sumber daya batubara sebesar 140 milyar ton, dengan produksi sebesar 461 juta ton pada tahun 2017 dan pemakaian domestik sebesar 97,03 juta ton (Anonim, 2018). Berdasarkan Rencana Umum Energi Nasional (RUEN) tahun 2017, konsumsi batubara untuk kebutuhan energi domestik akan terus naik hingga batas maksimumnya yaitu dikisaran 400 juta ton/tahun, sedangkan besaran produksi nasional direncanakan stabil di 400 juta ton/tahun hingga tahun 2050 (Anonim, 2017). Besarnya penggunaan batubara sebagai sumber energi dan adanya potensi sumber neodymium dari $C F A$ memberi peluang bagi Indonesia untuk dapat berperan aktif sebagai negara penghasil neodymium di dunia yang tentunya juga dapat mendukung kemandirian dan kedaulatan Bangsa Indonesia.

Di industri pertambangan dan pengolahan LTJ, proses pelindian LTJ biasanya menggunakan asam mineral seperti asam sulfat, asam nitrat, atau asam klorida. Penggunaan jenis asam ini dinilai masih memiliki beberapa kelemahan diantaranya menghasilkan gas berbahaya bagi lingkungan dan limbahnya tidak ramah terhadap lingkungan. Asam asetat digunakan sebagai pelindi dikarenakan sifatnya lebih ramah lingkungan (gas emisi lebih rendah dan lebih mudah terdegradasi oleh alam dibandingkan dengan asam anorganik) dan sudah terbukti dapat digunakan untuk mengekstraksi Nd (Behera dan Parhi, 2016).

Makalah ini akan membahas pengaruh konsentrasi dan suhu terhadap konsentrasi Nd yang terlindi, model kinetika reaksi dan parameter kinetik dari proses pelindian neodymium dari magnetik CFA dengan menggunakan asam asetat. Harapannya dapat menjadi sebuah langkah maju yang mendukung pengembangan riset dan teknologi industri pengolahan LTJ secara umum dan neodymium secara khusus di Indonesia.

\section{Metode Penelitian}

\subsection{Bahan Baku}

Coal fly ash (CFA) yang digunakan berasal dari PLTU Tanjung Awar-Awar, Tuban. Sampel CFA diayak dan diambil yang berukuran -400 mesh. Sampel kemudian diolah dengan magnetik separator untuk memisahkan bagian magnetik $C F A$ dari bagian nonmagnetiknya. Sampel magnetik $C F A$ ini yang akan digunakan dalam pelindian dengan asam asetat.

\subsection{Percobaan}

Dimasukkan $300 \mathrm{~mL}$ asam asetat $\left(\mathrm{CH}_{3} \mathrm{COOH}\right) 0,1 \mathrm{~N}$ ke dalam labu leher tiga yang dirangkai dengan pengaduk, termometer dan pendingin balik. Larutan asam asetat dimasukkan di dalam water bath pada suhu $26{ }^{\circ} \mathrm{C}$ dan diaduk dengan kecepatan putaran $400 \mathrm{rpm}$. Setelah suhu operasi tercapai, $15 \mathrm{~g}$ sampel magnetik $C F A$ dimasukkan ke dalam labu leher tiga. Dilakukan proses pengambilan sampel sebanyak $5 \mathrm{~mL}$ pada waktu pelindian $0,2,5,10$, 20, 30, 60, 120, dan 240 menit. Larutan sampel disentrifugasi dengan kecepatan 2000 rpm selama 5 menit, fase cairnya lalu disaring dengan filter. Diambil sebanyak $3 \mathrm{~mL}$ larutan lalu diencerkan dengan akuades hingga volumenya menjadi $10 \mathrm{~mL}$ untuk dianalisis dengan $I C P-A E S$. Analisis Neodymium dengan ICP-AES dilakukan pada panjang gelombang 430,358 nm dengan menggunakan larutan standar rare earth element mix for ICP yang diproduksi oleh Sigma-Aldridch. Proses percobaan secara keseluruhan dilakukan dengan variasi konsentrasi asam asetat $(0,1 \mathrm{~N}, 0,5 \mathrm{~N}$, dan $1 \mathrm{~N})$ dan suhu pelindian $\left(26^{\circ} \mathrm{C}, 40^{\circ} \mathrm{C}\right.$, dan $\left.60^{\circ} \mathrm{C}\right)$.

Data konsentrasi $\mathrm{Nd}$ hasil analisis dengan berbagai variasi konsentrasi larutan pelindi, suhu pelindian, dan waktu pelindian kemudian digunakan untuk menentukan pengaruh parameter dan memperkirakan model kinetika proses pelindian $\mathrm{Nd}$ dalam magnetik $C F A$, menentukan nilai konstanta kecepatan reaksi proses pelindian, dan energi aktivasinya.

\subsection{Pemilihan Model dan Perhitungan parameter kinetika}

Proses pelindian berlangsung berdasarkan reaksi heterogen antara padatan dengan cairan dengan mekanisme reaksi sebagai berikut (Behera dan Parhi, 2016):

$$
\mathrm{A}_{(\mathrm{aq})}+\mathrm{bB}_{(\mathrm{s})} \rightarrow \text { produk }
$$

Terdapat beberapa model untuk proses reaksi heterogen antara padatan dengan cairan, diantaranya yaitu progressive conversion model (PCM) dan shrinking core model (SCM). Sebagian besar proses reaksi heterogen antara padatan dengan cairan berlangsung mendekati pola SCM dibandingkan dengan PCM (Levenspiel, 1999). Shrinking core model pertama kali disusun oleh Yagi dan Kuni (1955, 1961) yang menggambarkan proses ini terdiri dari beberapa tahapan pada proses reaksi sebagai berikut.

Tahap 1. Difusi fluida A melalui lapisan cairan yang mengelilingi padatan B ke lapisan abu padatan B.

Tahap 2. Penetrasi dan difusi fluida A melalui lapisan abu ke permukaan inti padatan B yang belum bereaksi.

Tahap 3. Reaksi kimia fluida A dengan padatan B di permukaan inti padatan B yang belum bereaksi.

Tahap 4. Difusi produk melalui lapisan abu ke permukaan luar padatan.

Tahap 5. Difusi produk melalui lapisan fluida kembali ke badan utama fluida. 
Karena melibatkan banyak tahapan yang kecepatannya tidak sama dan seringkali berbeda jauh, kecepatan reaksi tergantung dari tahapan yang mengontrol reaksi. Untuk proses yang dikontrol oleh difusi pada lapisan cairan maka hubungan antara nilai konversi B dengan waktu menggunakan Persamaan (2). Untuk reaksi yang dikontrol oleh difusi pada lapisan abu, maka maka hubungan antara nilai konversi B dengan waktu menggunakan Persamaan (3). Untuk reaksi yang dikontrol oleh reaksi kimia yang terjadi pada permukaan inti padatan, maka maka hubungan antara nilai konversi B dengan waktu menggunakan Persamaan (4) (Levenspiel, 1999). Persamaan (2), (3), dan (4) yang menghubungkan nilai $X_{B}$ dengan waktu dapat dinyatakan dalam bentuk lain, secara berurutan dengan Persamaan (5), (6), dan (7) (Behera dan Parhi, 2016). Perbandingan persamaan yang menghubungkan nilai $t$ dengan $\mathrm{X}_{\mathrm{B}}$ dapat dilihat pada Tabel 1 .

Tabel 1. Perbandingan Model Persamaan yang menghubungkan nilai t dengan $\mathrm{X}_{\mathrm{B}}$

\begin{tabular}{llll}
\hline Model & \multicolumn{1}{c}{ (Levenspiel, 1999) } & \multicolumn{1}{c}{ (Behera dan Parhi, 2016) } \\
\hline $\mathrm{A}$ & $\frac{t}{\tau}=X_{\mathrm{B}}$ & $(2)$ & t. $\mathrm{k}_{\mathrm{ap}}=X_{\mathrm{B}}$ \\
$\mathrm{B}$ & $\frac{t}{\tau}=1-3\left(1-X_{B}\right)^{\frac{2}{3}}+$ & t. $\mathrm{k}_{\mathrm{ap}}=1-3\left(1-X_{\mathrm{B}}\right)^{\frac{2}{3}}+$ \\
& $2\left(1-X_{\mathrm{B}}\right)$ & $(3)$ & $2\left(1-X_{\mathrm{B}}\right)$ \\
$\mathrm{C}$ & $\frac{t}{\tau}=1-\left(1-X_{\mathrm{B}}\right)^{1 / 3}$ & (4) & t. $\mathrm{k}_{\mathrm{ap}}=1-\left(1-X_{\mathrm{B}}\right)^{1 / 3}$
\end{tabular}

Keterangan: (A) difusi lapisan asetat, $(B)$ difusi lapisan abu, (C) reaksi kimia di permukaan.

Persamaan (5), (6), dan (7) merupakan persamaan linier yang menghubungkan nilai $t$ dengan $X_{B}$. Berdasarkan grafik hubungan nilai $t$ dengan $X_{B}$ maka dapat diketahui model kinetika reaksi yang paling cocok untuk proses pelindian neodymium dalam magnetik $C F A$ dengan larutan pelindi asam asetat, yaitu model persamaan yang paling linier (memberikan nilai regresi paling mendekati 1).

Fraksi neodymium yang terambil dalam larutan dapat dihitung dengan Persamaan (8).

$$
X_{B}=\frac{\% N d \text { terlindi }}{100}
$$

Nilai konstanta kecepatan reaksi nyata untuk reaksi pelindian $\left(\mathrm{k}_{\mathrm{ap}}\right)$ dapat dicari berdasarkan grafik dari Persamaan (5) atau (6) atau (7), yang dipilih dari hasil kecocokan model persamaan dengan data percobaan yang telah dilakukan pada langkah sebelumnya. Energi aktivasi (E) dapat dicari berdasarkan grafik dari Persamaan (9) yang menggambarkan hubungan ln $\mathrm{k}_{\mathrm{ap}}$ dengan (1/T) (Behera dan Parhi, 2016).

$$
\ln k_{\mathrm{ap}}=\ln A-\left(\frac{E}{R}\right)\left(\frac{1}{\mathrm{~T}}\right)
$$

\section{Hasil dan Pembahasan}

\subsection{Pengaruh konsentrasi asam asetat}

Pengaruh konsentrasi asam asetat terhadap pelindian $\mathrm{Nd}$ dari magnetik CFA diamati dengan adanya variasi konsentrasi asam asetat sebagai larutan pelindi. Pada percobaan ini variasi konsentrasi asam asetat yang digunakan yaitu $0,1 \mathrm{~N}, 0,5 \mathrm{~N}$, dan $1 \mathrm{~N}$ dengan parameter lainnya dibuat tetap. Hasil pelindian $\mathrm{Nd}$ dengan varisasi konsentrasi asam asetat dapat dilihat pada Gambar 1. Dari gambar tersebut dapat dilihat bahwa Nd yang terlindi naik dari $51 \%$ hingga $67 \%$ seiring dengan kenaikan konsentrasi dari $0,1 \mathrm{~N}$ hingga $1,0 \mathrm{~N}$.

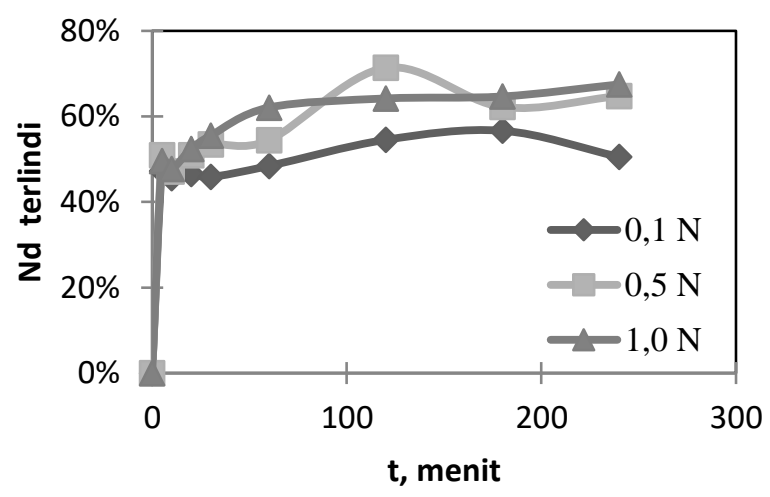

Gambar 1. Pengaruh konsentrasi asam asetat terhadap pelindian Nd (kondisi: $400 \mathrm{rpm}, 3,75 \% \mathrm{~S} / \mathrm{L}$, suhu $80{ }^{\circ} \mathrm{C}$ )

\subsection{Pengaruh suhu}

Pengaruh suhu pelindian Nd dari magnetik CFA diamati dengan adanya variasi suhu pelindian. Pada percobaan ini variasi suhu pelindian $\mathrm{Nd}$ dilakukan pada suhu $26{ }^{\circ} \mathrm{C}$, $40{ }^{\circ} \mathrm{C}$, dan $60^{\circ} \mathrm{C}$ dan parameter lainnya dibuat tetap. Hasil pelindian $\mathrm{Nd}$ dengan variasi suhu pelindian dapat dilihat pada Gambar 2. Dari gambar tersebut dapat dilihat bahwa $\mathrm{Nd}$ yang terlindi naik dari $62 \%$ sampai $72 \%$ seiring dengan kenaikan suhu dari $26{ }^{\circ} \mathrm{C}$ sampai $60{ }^{\circ} \mathrm{C}$.

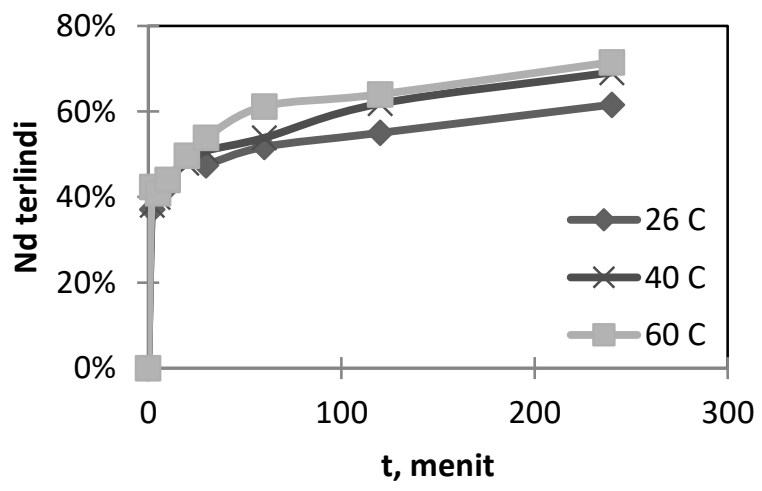

Gambar 2. Pengaruh suhu pelindian terhadap pelindian $\mathrm{Nd}$ (kondisi: $400 \mathrm{rpm}, 3,75 \% \mathrm{~S} / \mathrm{L}$, Asam asetat 0,5 N) 
Menurut Behera dan Parhi (2016) proses pelindian Nd dengan asam asetat merupakan proses endotermik, sehingga kenaikan suhu akan mengakibatkan kenaikan jumlah Nd yang terlindi.

\subsection{Penentuan model dan parameter kinetika}

Reaksi antara neodymium dengan asam asetat berjalan menurut reaksi berikut (Zanonato dkk., 2001):

$\mathrm{Nd}^{3+}+\mathrm{j} \mathrm{CH}_{3} \mathrm{COO}^{-} \leftrightarrow \mathrm{Nd}\left(\mathrm{OOCCH}_{3}\right)_{\mathrm{j}}{ }^{(3-\mathrm{j})+} \quad \mathrm{j}=1,2,3$

Reaksi tersebut merupakan reaksi heterogen antara asama asetat yang berbentuk cairan dengan neodymium dalam magnetik $C F A$ yang berbentuk padatan. Pemilihan model dibatasi hanya pada tiga pilihan model dengan beberapa kondisi dan asumsi yaitu: magnetik CFA merupakan partikel berbentuk bola yang bersifat nonporos, reaksi terjadi di permukaan padatan, ada lapisan abu yang terbentuk atau tersisa setelah proses pelindian (dibuktikan dari hasil percobaan).

Hasil plot persamaan Persamaan (5), (6), dan (7), yang merupakan persamaan linier yang menghubungkan nilai $\mathrm{t}$ dengan $\mathrm{X}_{\mathrm{B}}$ dapat dilihat pada Gambar 3. Dari gambar tersebut kemudian dapat diketahui nilai $\mathrm{R}^{2}$ untuk tiap persamaan yang dapat dilihat pada Tabel 2. Dari tabel tersebut dapat dilihat bahwa model persamaan yang paling cocok dengan data hasil percobaan adalah model SCM yang dikontrol oleh difusi pada lapisan abu. Hal ini ditandai dengan nilai $\mathrm{R}^{2}$ yang paling mendekati satu yaitu sebesar 0,8196. Dengan demikian maka persamaan yang paling menggambarkan pelindian neodymium dari magnetik CFA dengan asam asetat adalah Persamaan (6) yaitu: $\left[\left(\right.\right.$ t. $\left.\mathrm{k}_{\mathrm{ap}}=1-3\left(1-X_{\mathrm{B}}\right)^{\frac{2}{3}}+2\left(1-X_{\mathrm{B}}\right)\right]$.

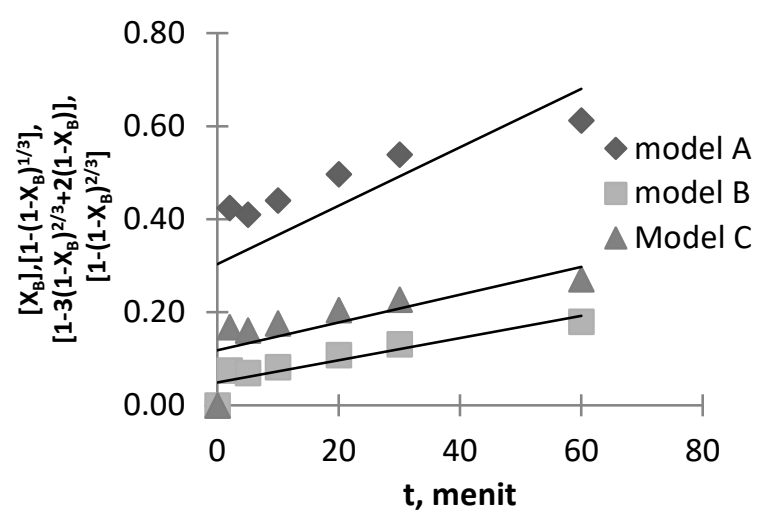

Gambar 3. Kecocokan data percobaan dengan model persamaan kinetik: difusi lapisan asetat (A), difusi lapisan abu (B), reaksi kimia di permukaan $(\mathrm{C})$.

Tabel 2. Nilai $\mathrm{R}^{2}$ untuk model kinetika: (A) difusi lapisan asetat, (B) difusi lapisan abu, $(\mathrm{C})$ reaksi kimia di permukaan padatan

\begin{tabular}{cccc}
\hline Elemen & \multicolumn{3}{c}{ Nilai R $^{2}$} \\
\cline { 2 - 4 } & Model A & Model B & Model C \\
Nd & 0,4600 & 0,8196 & 0,5548 \\
\hline
\end{tabular}

Hasil plot Persamaan (6) yang menggambarkan hubungan nilai neodymium yang terlindi dengan waktu pelindian untuk suhu yang berbeda dapat dilihat pada Gambar 4. Dari grafik tersebut diperoleh persamaan garis yang mengandung nilai konstanta kecepatan reaksi untuk proses pelindian $\mathrm{Nd}$ dengan asam asetat yang dapat dilihat pada Tabel 3.

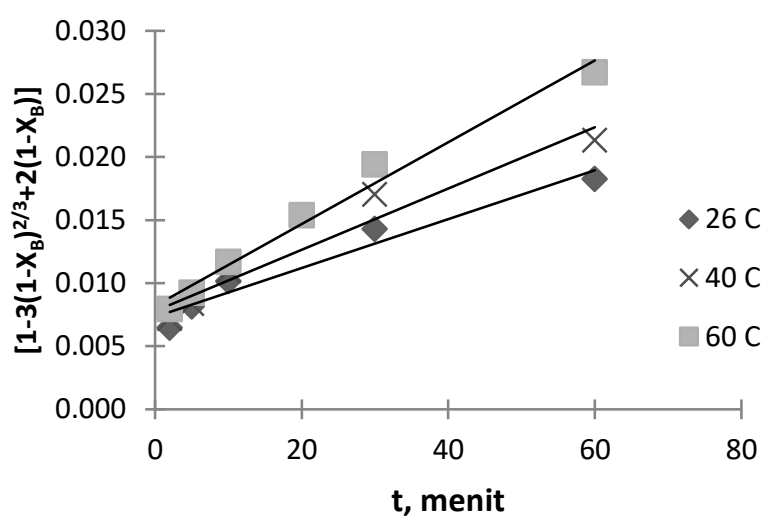

Gambar 4. Penerapan model SCM yang dikontrol difusi lapisan abu untuk pelindian $\mathrm{Nd}$ pada suhu berbeda

Tabel 3. Nilai $k_{a p}$ berdasarkan grafik persamaan yang menghubungkan nilai t dengan $\mathrm{X}_{\mathrm{B}}$ pada suhu yang berbeda

\begin{tabular}{ccccc}
\hline \multicolumn{2}{c}{ Suhu Pelindian (T) } & & Persamaan garis & Kap \\
\cline { 1 - 2 }${ }^{{ }^{\mathbf{0}} \mathbf{C}}$ & $\mathbf{K}$ & & \\
26 & 299 & $\mathrm{y}=1,04 \mathrm{E}-03 \mathrm{x}+6,04 \mathrm{E}-02$ & $1,04 \mathrm{E}-03$ \\
40 & 313 & $\mathrm{y}=1,23 \mathrm{E}-03 \mathrm{x}+6,58 \mathrm{E}-02$ & $1,23 \mathrm{E}-03$ \\
60 & 333 & $\mathrm{y}=1,94 \mathrm{E}-03 \mathrm{x}+6,66 \mathrm{E}-02$ & $1,94 \mathrm{E}-03$
\end{tabular}

Hasil plot Persamaan (9) yang menghubungkan nilai konstanta kecepatan reaksi untuk proses pelindian dengan suhu (1/T) dapat dilihat pada Gambar 5. Dari grafik tersebut diperoleh persamaan garis yang mengandung nilai energi aktivasi (E) yaitu sebesar 15,38 kJ/mol.

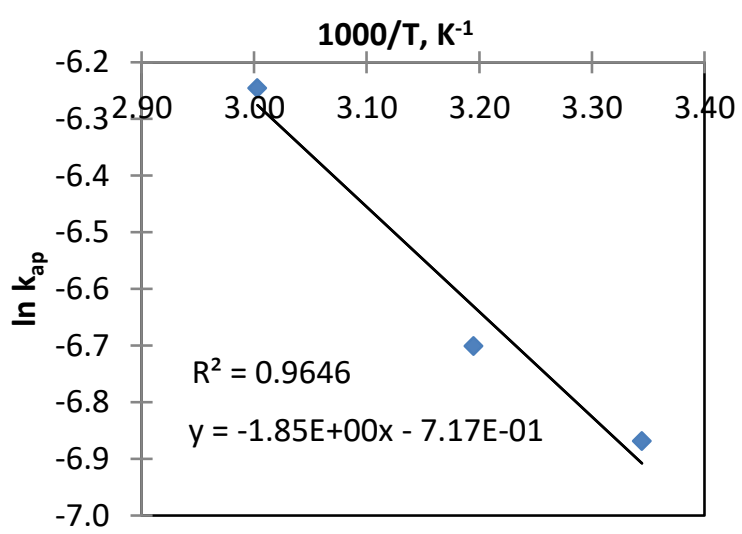

Gambar 5. Grafik persamaan arrhenius untuk pelindian Nd. 
Nilai energi aktivasi dari pelindian $\mathrm{Nd}$ dalam magnetik CFA dengan asam asetat pada penelitian ini adalah $15,38 \mathrm{~kJ} / \mathrm{mol}$. Hasil ini sesuai dengan penelitian sebelumnya, Habashi dalam Gustiana (2018) menyatakan bahwa difusi merupakan tahapan yang dominan dalam mengendalikan pelindian jika nilai energi aktivasinya sebesar 4,2 -12,6 kJ/mol dan reaksi kimia yang mengendalikan pelindian jika nilai energi aktivasinya $>42$ $\mathrm{kJ} / \mathrm{mol}$.

\section{Kesimpulan}

Dari hasil percobaan dapat disimpulkan bahwa kenaikan jumlah $\mathrm{Nd}$ yang terlindi dipengaruhi oleh kenaikan suhu pelindian dan kenaikan konsentrasi asam asetat. Jumlah pelindian Nd yang terbesar (72\%) diperoleh pada suhu $60{ }^{\circ} \mathrm{C}$ dan konsentrasi asam asetat $0,5 \mathrm{~N}$. Hasil percobaan menunjukkan bahwa pelindian $\mathrm{Nd}$ dalam magnetik $C F A$ dengan asam asetat mengikuti persamaan SCM yang dikontrol oleh difusi lapisan abu $\left[\mathrm{t} . \mathrm{k}_{\mathrm{ap}}=1-3\left(1-\mathrm{X}_{\mathrm{B}}\right)^{2 / 3}+2\left(1-\mathrm{X}_{\mathrm{B}}\right)\right]$, dengan energi aktivasi sebesar $15,38 \mathrm{~kJ} / \mathrm{mol}$.

\section{Ucapan Terima Kasih}

Terima kasih sebesar-besarnya kepada: PusdiklatBATAN yang telah memberikan beasiswa dan dana penelitian, Puslitbang tekMIRA-Bandung untuk izin pemanfaatan alat magnetik separator, juga kepada segenap dosen dan mahasiswa Sustainable Mineral Processing Research Group di Departemen Teknik Kimia UGM atas bantuannya, sehingga penelitian ini dapat terlaksana.

\section{Daftar Notasi}

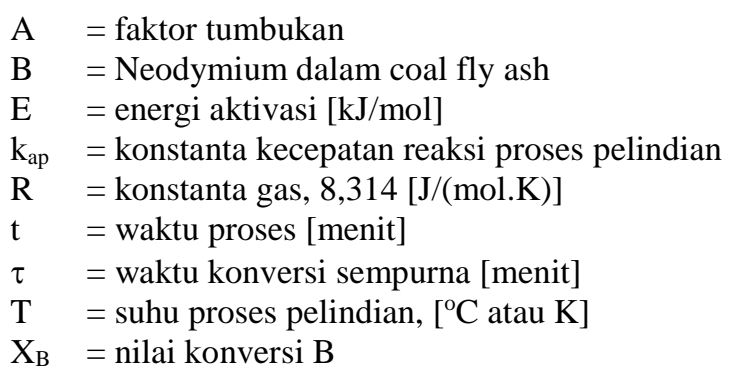

\section{Daftar Pustaka}

Anonim. Laporan kinerja 2017 Dirjen Minerba, Kementrian ESDM. 2018.

Anonim. Peraturan Presiden RI Nomor 22 Tahun 2017 Tentang Rencana Umum Energi Nasional. 2017.

Behera S.S. dan P.K. Parhi, 2016, Leaching kinetics study of neodymium from the scrap magnet using acetic acid. Separation and Purification Technology, 60: 59-66.
Belkin, H E., Susan J.T., James C.H., J.D. Stucker, J.M.K. O'Keefe, 2009, Geochemistry and petrology of selected coal samples from Sumatra, Kalimantan, Sulawesi, and Papua, Indonesia. International Journal of Coal Geology, Vol 77, 260-268.

Blisset, R.S., N. Smalley, N.A. Rowson, 2014, An Investigation into six coal fly ashes from the united kingdom and Poland to evaluate rare earth element content. Fuel, Vol 119, 236-239.

Croat J.J. Rapidly solidified neodymium-Iron-Boron permanent magnets. Woodhead Publishing: Duxford. 2018: p.5

Dai S., Yaofa J., Colin R.W., Landing G., Vladimir V.S., Huidong L., Dao Z., Xibo W., Yuzhuang S., Juanhua Z., Deyi R., 2012, Mineralogical and geochemical compositions of the coal in the Guanbanwusu Mine, Inner Mongolia, China: Further evidence for the existence of an $\mathrm{Al}$ ( $\mathrm{Ga}$ and REE) ore deposit in the Jungar Coalfield, International Journal of Coal Geology, Vol 98, 10-40.

Eskenazy, G.M., 1987, Rare earth elements in a sampled coal from the Pirin deposit, Bulgaria, International Journal of Coal Geology, 7, 301-314.

Gergoric M., C. Ravaux, B.M. Steenari, F. Espegren, T. Retegan, 2018, Leaching and Recovery of Rare-Earth Elements from Neodymium Magnet Waste Using Organic Acids. Metal, 8, 1-17

Gustiana, H. S., 2018, Pelindian Nikel dari Nikel Laterit Pomalaa Menggunakan Asam Asetat. Yogyakarta: Universitas Gadjah Mada,

Jha A.R., 2014, Rare earth materials, properties and aplications. CRC Press: Boca Raton.

Levenspiel, O., 1999, Chemical reaction engineering 3rd ed. John wiley \& sons: New york.

Seredin, V. V., 2016, Rare earth element-bearing coals from the Russian Far East deposits. International Journal of Coal Geology, Vol 30, 101-129.

Voncken J.H.L. The Rare earth elements an Introduction. Springer. 2016: 116.

Yagi, S., and Kunii, D., 1955, 5th Symposium

(International) on Combustion, Reinhold, New York, 231.

Yagi, S., and Kunii, D., Chem. Eng. Sci., 16, 1961, 364, $372,380$.

Zanonato, P.L., Bernardo, P., Bismondo, A., Rao, L., Choppin, G.R., 2001, Thermodynamic Studies of the Complexation between Neodymium and Acetate at Elevated Temperatures, Journal of Solution Chemistry, Vol. 30, 1-18.

Zepf V., 2013, Rare earth elements, a new approach to the nexus of supply, demand and use: exemplified along the use of neodymium in permanent magnets. University of Augsburg, Germany, Doctoral Thesis. 